\title{
Inhibition of DUSP13B Phosphatase Activity by PTP Inhibitor V
}

\author{
Jaehee Choun, Younghyun Kim, and Sayeon Cho* \\ College of Pharmacy, Chung-Ang University, Seoul 156-756, Korea. *E-mail: sycho@cau.ac.kr \\ Received June 4, 2014, Accepted June 23, 2014
}

Key Words : DUSP13B, PTP inhibitor V, PTP, PTP inhibitor

Protein tyrosine phosphorylation is a reversible posttranslational modification that plays an important role in signal transduction pathways. ${ }^{1}$ The phosphorylation state of a protein is a result of coordinated action of protein kinases and protein phosphatases. Protein phosphatases are known to mainly control the rate and duration of the signals, while protein kinases are known to control the amplitude of the signals. $^{2}$ Protein phosphatases can be divided into three groups according to their sequence, structure, and catalytic mechanism: classic Ser/Thr phosphatases, protein Tyr phosphatases (PTP), and the Asp-based protein phosphatases. ${ }^{3}$ Dual-specificity phosphatases (DUSPs) are a subfamily of PTP, which dephosphorylate phospho-Ser, -Thr, and -Tyr.

The DUSP13 gene located on chromosome 10q22.2 encodes two atypical DUSPs: DUSP13A/MDSP (musclerestricted DUSP) and DUSP13B/TMDP (testis- and skeletal muscle-specific DUSP). These two distinct proteins are synthesized from alternative open reading frames of DUSP13 gene. DUSP13A/MDSP protein is expressed mostly in skeletal muscle but also expressed in human neuroblastoma SK-N-SH cells. ${ }^{4}$ DUSP13B/TMDP protein expression is abundant in testis especially in spermatocytes and round spermatids but the cellular targets of DUSP13A and B are yet to be characterized. ${ }^{5}$

PTP inhibitor V (PhenylHydrazonoPyrazolone Sulfonate 1 , PHPS1) is a small-molecular-weight compound known as a mimetic of phoshotyrosine (Fig. 1). Previous studies reported that PTP inhibitor $\mathrm{V}$ inhibits the phosphatase activity of several PTPs including SHP- $2,{ }^{6}$ DUSP $14,{ }^{7}$ PTPN $2,{ }^{8}$ and DUSP13A. ${ }^{9}$ These PTPs exhibit the half maximal inhibitory concentration $\left(\mathrm{IC}_{50}\right)$ value of $2.1,3.9,3.79$, and $3.64 \mu \mathrm{M}$, respectively.

In this study, we tested other recombinant PTPs by in vitro

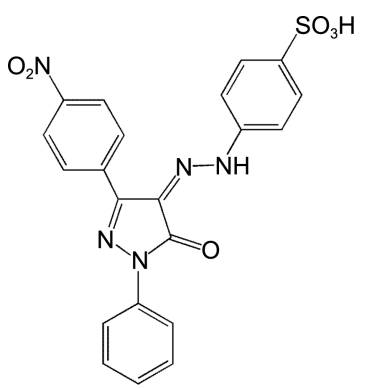

Figure 1. Chemical structure of PTP inhibitor V. 4- $\left\{N^{\prime}-[3-(4-\right.$ nitrophenyl)-5-oxo-1-phenyl-1,5-dihydro-pyrazol-(4Z)-ylidene]hydrazino\}-benzenesulfonic acid. phosphatase assay if they could be targets of PTP inhibitor $\mathrm{V}$. We observed the reduced activity of DUSP13B by PTP inhibitor $\mathrm{V}$ while the activities of $\mathrm{Cdc} 25 \mathrm{~A}$ and $\mathrm{Cdc} 25 \mathrm{~B}$ were not affected when treated with PTP inhibitor V (Table 1).

To determine the $\mathrm{IC}_{50}$ value of PTP inhibitor $\mathrm{V}$ on DUSP13B, we plotted a dose-response curve by using curve fitting program Prism 3.0 (GraphPad Software). The $\mathrm{IC}_{50}$ value of DUSP13B was identified as $1.77 \pm 0.21 \mu \mathrm{M}$ (Fig. 2(a)). From these data, we concluded that PTP inhibitor $\mathrm{V}$ is more effective inhibitor of DUSP13B when compared to the previously known inhibitor NSC663284 $\left(\mathrm{IC}_{50}=3.84 \pm 0.86\right.$ $\mu \mathrm{M}) .^{10}$

We next confirmed the inhibition mechanism of PTP inhibitor V on DUSP13B by kinetic measurements based on Michaelis-Menten equation. The Lineweaver-Burk plots show that the maximum reaction velocity $\left(V_{\max }\right)$ is constant regardless of the presence of the inhibitor. This result indicates that PTP inhibitor V binds to the active site of DUSP13B and functions as a competitive inhibitor of DUSP13B (Fig. $2(\mathrm{~b}))$. The calculated inhibition constant $\left(K_{\mathrm{i}}\right)$ value was 6.36 $\mu \mathrm{M}$.

To clarify the inhibitory effect of PTP inhibitor $\mathrm{V}$ on intact DUSP13B expressed in the mammalian cells, human embryonic kidney 293 (HEK 293) cells were transfected with FLAG-tagged DUSP13B expression plasmid and incubated for $48 \mathrm{~h}$. Then the cells were harvested and lysed with PTP lysis buffer. FLAG-DUSP13B was immunoprecipitated from cell lysates by anti-FLAG M2 affinity gel. Immunoprecipitated DUSP13B was incubated with or without PTP inhibitor $\mathrm{V}$ and the phosphatase activities of DUSP13B were measured by using 3-O-methylfluorescein phosphate (OMFP) as a substrate. Since PTP inhibitor V is hardly soluble in Dulbecco's modified Eagle's medium (DMEM), we decided to treat the inhibitor to the immunoprecipitated DUSP13B. The phosphatase activity of DUSP13B decreased as the

Table 1. Inhibition of PTPs by PTP inhibitor V

\begin{tabular}{cc}
\hline Protein Tyrosine Phosphatase & $\mathrm{IC}_{50}(\mu \mathrm{M})$ \\
\hline DUSP13B & $1.77 \pm 0.21$ \\
Cdc25A & $>10$ \\
Cdc25B & $>10$ \\
\hline
\end{tabular}

$\mathrm{IC}_{50}$ values of enzyme activity were determined for the various recombinant PTPs. PTPs were incubated with 0 or $10 \mu \mathrm{M}$ of PTP inhibitor $\mathrm{V}$ at $37^{\circ} \mathrm{C}$ for $30 \mathrm{~min}$. Fluorescence emission was measured by a multiwell plate reader (excitation filter, $485 \mathrm{~nm}$; emission filter, $535 \mathrm{~nm}$ ) 
(a)
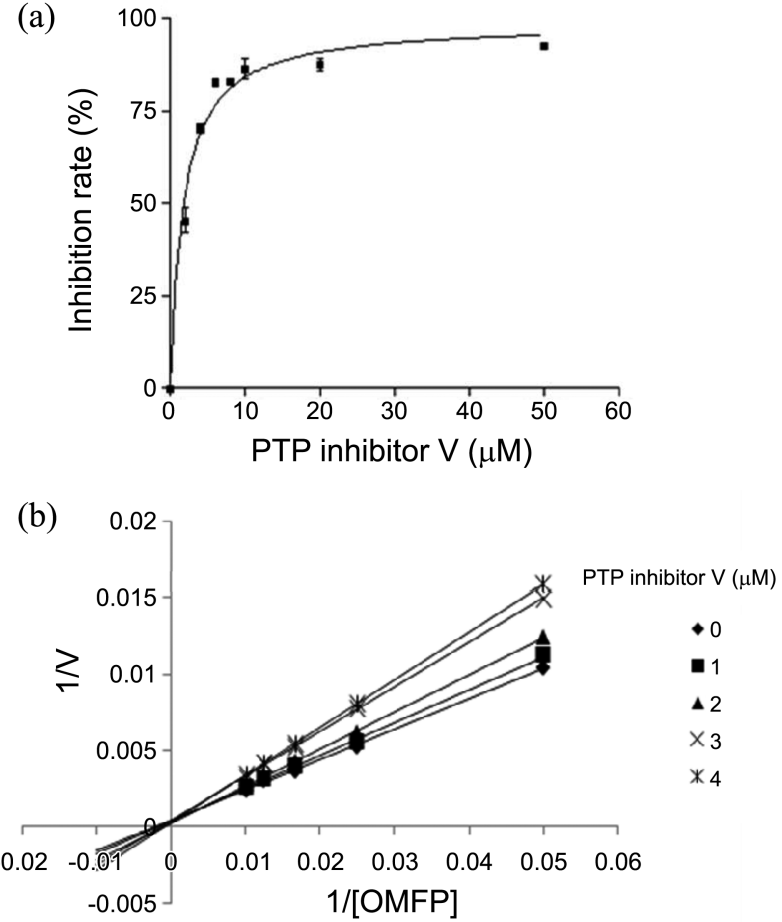

Figure 2. Inhibition of PTP inhibitor V on recombinant DUSP13B. (a) DUSP13B (100 nM) was incubated with various concentrations of PTP inhibitor $\mathrm{V}$ and OMFP at $37^{\circ} \mathrm{C}$ for $30 \mathrm{~min}$. Fluorescence emission was measured by a multi-well plate reader as described in the experimental section. (b) Kinetics analysis was performed based on Lineweaver-Burk plot. Lineweaver-Burk plots were generated from the reciprocal data.

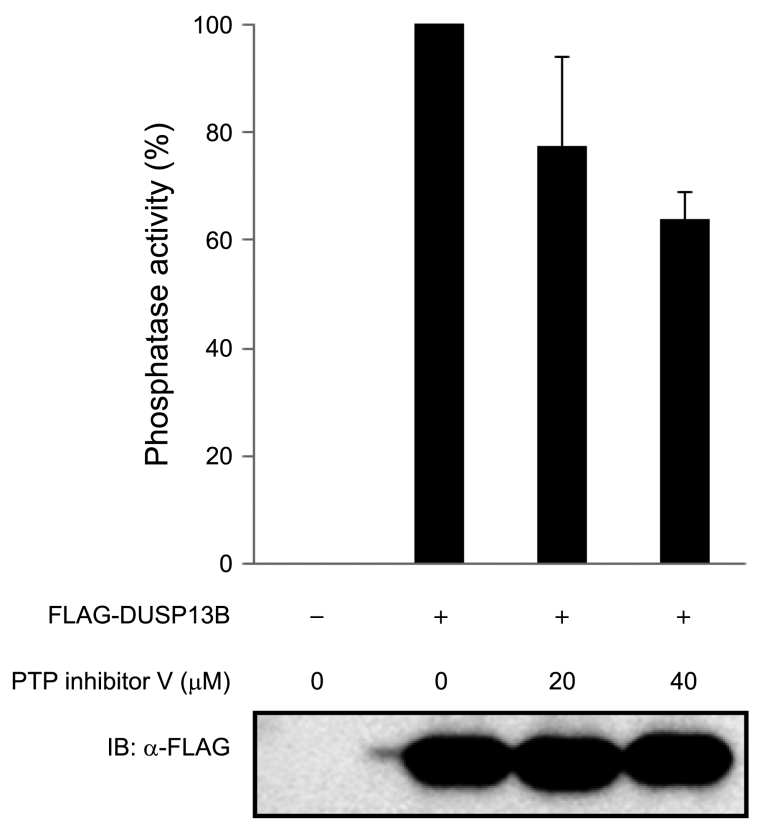

Figure 3. Inhibitory effect of PTP inhibitor $\mathrm{V}$ on DUSP13B purified from HEK 293 cells. HEK 293 cells were transfected with FLAG-DUSP13B expression plasmid. After $48 \mathrm{~h}$, cell lysates were incubated with anti-FLAG M2 affinity gel. Then the immunoprecipitated DUSP13B was incubated with various concentrations of PTP inhibitor V $(0,20,40 \mu \mathrm{M})$ at $37^{\circ} \mathrm{C}$ for $30 \mathrm{~min}$. Fluorescence emission was measured by a multi-well plate reader. concentration of PTP inhibitor V increased (Fig. 3). This result indicates that PTP inhibitor $\mathrm{V}$ inhibits both the recombinant DUSP13B expressed in Escherichia coli and the intact DUSP13B expressed in HEK 293 cell line.

There are only a few studies done on DUSP13B. The recent study reported that DUSP13B induces inactivation of stress-activated JNK and p38 and suppresses AP-1-dependent gene expression. When cellular stress induces germ cell loss in seminiferous tubules, DUSP13B inhibits over-activation of JNK/AP-1 in testis and maintains germ cell reproduction. ${ }^{11}$ PTP inhibitor $V$ could be a useful tool for the study of the role of DUSP13B on the maintenance of the germ cell reproduction under cellular stresses. The cellular targets of DUSP13B are yet to be characterized. PTP inhibitor V could facilitate the finding of the functions and the cellular targets of DUSP13B.

\section{Experimental Section}

Antibodies and Reagents. Monoclonal anti-FLAG M2 antibody was purchased from Sigma-Aldrich (St. Louis, $\mathrm{MO}$ ). Linear polyethylenimine (PEI) was purchased from Polysciences (Warrington, PA, USA). PTP inhibitor V was purchased from Merck KGaA (Darmstadt, Germany).

Cell Culture and Transfection. HEK 293 cells were cultured in DMEM (Thermo Scientific, Waltham, MA) supplemented with $10 \%$ fetal bovine serum (FBS, Thermo Scientific) and $1 \%$ penicillin/streptomycin in a $5 \% \mathrm{CO}_{2}$ incubator. The day before transfection, $1 \times 10^{6}$ cells were plated in $60 \mathrm{~mm}$ cell culture dish and were allowed to adhere overnight. The cells were transfected with FLAG-DUSP13B using PEI.

Purification of Recombinant Protein. His-tagged DUSP13B was constructed in pET28a (+) plasmid (Novagen, Darmstadt, Germany) and transformed into BL21 (DE3)-RIL Escherichia coli. Recombinant protein was induced by 1 $\mathrm{mM}$ isopropyl $\beta$-D-1-thiogalactopyranoside (IPTG) at $37{ }^{\circ} \mathrm{C}$ for $3 \mathrm{~h}$. Cells were harvested and then lysed by sonication in $50 \mathrm{mM}$ Tris- $\mathrm{HCl}$ (pH 6.8), $300 \mathrm{mM} \mathrm{NaCl}, 1 \%$ IGEPAL CA630 (NP-40), $1 \mathrm{mM}$ phenylmethanesulfonyl fluoride (PMSF). The lysates were clarified by centrifugation at $10,000 \mathrm{rpm}$ for $20 \mathrm{~min}$ at $4{ }^{\circ} \mathrm{C}$. The supernatant was applied to a column filled with Ni-NTA resin (PEPTRON, Daejeon, Korea). The resin was washed with the buffer containing $20 \mathrm{mM}$ Tris$\mathrm{HCl}$ (pH 8.0), $500 \mathrm{mM} \mathrm{NaCl}, 50 \mathrm{mM}$ imidazole and eluted with the buffer containing $20 \mathrm{mM}$ Tris- $\mathrm{HCl}(\mathrm{pH} \mathrm{8.0)}, 500$ $\mathrm{mM} \mathrm{NaCl}, 200 \mathrm{mM}$ imidazole.

In vitro Phosphatase Assays and Kinetic Analysis. Phosphatase activity was measured by using OMFP (SigmaAldrich) as a substrate in a 96-well microtiter plate. The assay was based on methods described previously. ${ }^{12}$ PTP inhibitor V and OMFP were solubilized in dimethyl sulfoxide (DMSO). All reactions were performed at the final concentration of $1 \%$ DMSO. The final reaction mixture (100 $\mu \mathrm{L}$ ) was optimized for enzyme activity and composed of 30 $\mathrm{mM}$ Tris-HCl ( $\mathrm{pH} 7.0$ ), $75 \mathrm{mM} \mathrm{NaCl}, 1 \mathrm{mM}$ ethylenediaminetetraacetic acid (EDTA), $0.1 \mathrm{mM}$ dithiothreitol (DTT), 
$0.33 \%$ bovine serum albumin (BSA) and $100 \mathrm{nM}$ of PTPs. Reactions were initiated by addition of OMFP and incubated for $30 \mathrm{~min}$ at $37^{\circ} \mathrm{C}$. Fluorescence emission from the product was measured by a multi-well plate reader (Biotek, excitation filter, $485 \mathrm{~nm}$; emission filter, $535 \mathrm{~nm}$ ). The reaction was linear over the time period of the experiment and was directly proportional to both enzyme and substrate concentrations. $\mathrm{IC}_{50}$ value was defined as the concentration of an inhibitor that caused a $50 \%$ decrease in the activity of PTP. $\mathrm{IC}_{50}$ values and the best curve fit for Lineweaver-Burk plots were determined by using the curve fitting program Prism 3.0 (GraphPad Software, San Diego, CA). All experiments were performed in triplicate and repeated at least three times.

Immunoblotting Analysis. Cell lysates were run in 10\% sodium dodecyl sulfate (SDS)-polyacrylamide gel and transferred to nitrocellulose membrane (Whatman, Springfield Mill, UK). The membrane was blocked with 5\% skim milk for $1 \mathrm{~h}$ and incubated with the appropriate primary antibodies, followed by incubation with the appropriate secondary antibodies conjugated with horseradish peroxidase (HRP). The protein bands were visualized by the ECL detection system (Pierce, Rockford, IL).

Immunoprecipitation and in vitro Phosphatase Activity Assay. HEK 293 cells were transiently transfected with FLAGDUSP13B expression plasmid. After $48 \mathrm{~h}$ of incubation, cells were washed with phosphate buffered saline ( $\mathrm{pH} 7.4$ ) to remove the remaining inhibitor on the cells. Then the cells were lysed with PTP lysis buffer containing 0.5\% NP-40, $0.5 \%$ Triton $\mathrm{X}-100,150 \mathrm{mM} \mathrm{NaCl}, 20 \mathrm{mM}$ Tris- $\mathrm{HCl}$ (pH 8.0), $1 \mathrm{mM}$ EDTA, $1 \%$ glycerol, $1 \mathrm{mM}$ PMSF and $3 \mu \mathrm{M}$ DTT for $15 \mathrm{~min}$ at $4{ }^{\circ} \mathrm{C}$. Cell lysates were clarified by centrifugation at $13,000 \mathrm{rpm}$ for $30 \mathrm{~min}$ at $4{ }^{\circ} \mathrm{C}$ and the supernatant were incubated with anti-FLAG M2 affinity gel on a rotator for $3 \mathrm{~h}$ at $4{ }^{\circ} \mathrm{C}$. After binding, the beads were washed with lysis buffer and the bound proteins were incubated with various concentrations of PTP inhibitor V and OMFP. The reaction buffer was comprised of $30 \mathrm{mM}$ Tris- $\mathrm{HCl}$ ( $\mathrm{pH} 7.0$ ), $75 \mathrm{mM} \mathrm{NaCl}, 1 \mathrm{mM}$ EDTA, $0.1 \mathrm{mM}$ DTT, $0.33 \%$ BSA. The reaction mixtures were incubated at $37^{\circ} \mathrm{C}$ for $30 \mathrm{~min}$ and the fluorescence were measured by multi-well plate reader (excitation filter, $485 \mathrm{~nm}$; emission filter, $535 \mathrm{~nm})$.

Inhibition Study. The inhibition constant $\left(K_{\mathrm{i}}\right)$ to DUSP13B for the inhibitor was determined by measuring the initial rates at several OMFP concentrations for each fixed concentration of the inhibitor. The data were fitted to the following equation to obtain the $K_{\mathrm{i}}$ value of reversible competitive inhibitors. The obtained slopes were replotted against the inhibitor concentrations. The $K_{\mathrm{i}}$ value was obtained from the slopes of these replots. ${ }^{13}$

$$
1 / V=K_{\mathrm{m}}\left(1+[\mathrm{I}] / K_{\mathrm{i}}\right) V_{\max }[\mathrm{S}]+1 / V_{\max }
$$

Acknowledgments. This research was supported by the Chung-Ang University Excellent Student Scholarship and in 2013 and by the National Research Foundation of Korea (NRF) grant funded by the Korea government (MEST) (NRF2012R1A2A2A01047338 and NRF-2012R1A1B3001937).

\section{References}

1. Ostman, A.; Hellberg, C.; Bohmer, F. D. Nat. Rev. Cancer. 2006, $6,307$.

2. Heinrich, R.; Neel, B. G.; Rapoport, T. A. Molecular Cell 2002, 9 , 957.

3. Moorhead, G. B.; Trinkle-Mulcahy, L.; Ulke-Lemee, A. Nat. Rev. Mol. Cell Biol. 2007, 8, 234.

4. Park, J. E.; Park, B. C.; Kim, H. A.; Song, M.; Park, S. G.; Lee do, H.; Kim, H. J.; Choi, H. K.; Kim, J. T.; Cho, S. Cell Mol. Life Sci. 2010, 67, 2619.

5. Chen, H. H.; Luche, R.; Wei, B.; Tonks, N. K. J. Biol. Chem. 2004, 279, 41404.

6. Hellmuth, K.; Grosskopf, S.; Lum, C. T.; Wurtele, M.; Roder, N.; von Kries, J. P.; Rosario, M.; Rademann, J.; Birchmeier, W. Proc. Natl. Acad. Sci. USA 2008, 105, 7275.

7. Seo, H.; Cho, S. Bull. Korean Chem. Soc. 2013, 34, 3871.

8. Kim, Y.; Cho, S. Bull. Korean Chem. Soc. 2013, 34, 3874.

9. Youn, D.; Cho, S. Bull. Korean Chem. Soc. 2013, 34, 3912.

10. Lee, I. S.; Ju, A.; Cho, S. Bull. Korean Chem. Soc. 2012, 33, 3505.

11. Katagiri, C.; Masuda, K.; Nomura, M.; Tanoue, K.; Fujita, S.; Yamashita, Y.; Katakura, R.; Shiiba, K.; Nomura, E.; Sato, M.; Tanuma, N.; Shima, H. Molecular and Cellular Biochemistry 2011, 352, 155 .

12. Tierno, M. B.; Johnston, P. A.; Foster, C.; Skoko, J. J.; Shinde, S. N.; Shun, T. Y.; Lazo, J. S. Nat. Protoc. 2007, 2, 1134.

13. Shi, Z.; Tabassum, S.; Jiang, W.; Zhang, J.; Mathur, S.; Wu, J.; Shi, Y. Chembiochem 2007, 8, 2092. 